\title{
Statistical-based optimization and scale-up of siderophore production process on laboratory bioreactor
}

\author{
S. S. Shaikh ${ }^{1}$ S. J. Wani ${ }^{1} \cdot$ R. Z. Sayyed ${ }^{1}$
}

Received: 16 September 2015/ Accepted: 8 January 2016/Published online: 15 February 2016

(C) The Author(s) 2016. This article is published with open access at Springerlink.com

\begin{abstract}
We report the enhanced production of siderophore in succinate medium by applying two-stage statistical approach, i.e., Plackett-Burman design and response surface methodology (RSM) using central composite design (CCD). In the first stage of optimization, out of 11 variable components of succinate medium, succinic acid, $\mathrm{pH}$ and temperature were found as significant components that influenced the siderophore production in Pseudomonas aeruginosa RZS9. The second stage of RSM using CCD consisted of optimizing the concentrations of the variables. Here, $0.49 \mathrm{~g} / 100 \mathrm{ml}$ concentration of succinic acid, pH 7.08 and temperature of $27.80{ }^{\circ} \mathrm{C}$ yielded the maximum $(68.41 \%)$ siderophore units. All the significant components exhibited quadratic effect on siderophore production. The $F$ value of 28.63 , multiple correlation coefficient $\left(R^{2}\right)$ of 0.9626 , percent coefficient of variation of 8.81 values indicated that the model was significant and that the experimental data was satisfactorily adjusted to the quadratic model. During validation of these experiments, $6.10 \%$ increase in siderophore yield was obtained. Scaleup of this protocol optimized at shake flask level up to 5 L-capacity reactor further enhanced the siderophore yield. We claim it to be the first report on statistical optimization of siderophore production by $P$. aeruginosa RZS9.
\end{abstract}

Electronic supplementary material The online version of this article (doi:10.1007/s13205-016-0365-2) contains supplementary material, which is available to authorized users.

\section{R. Z. Sayyed}

riyaz829@yahoo.co.in; sayyedrz@gmail.com

1 Department of Microbiology, PSGVP Mandal's, Arts, Science and Commerce College, Shahada, Dist Nandurbar, Maharashtra 425 409, India
Keywords Optimization · Plackett-Burman (PB) design · Response surface methodology (RSM) - Scale up · Siderophore

\section{Introduction}

Siderophores are low-molecular-weight, iron-scavenging ligands produced by a wide variety of microorganisms to combat iron deficiency (Sayyed et al. 2013). Siderophores of rhizobacteria provide iron nutrition to the plants and help in plant-growth promotion. They prevent the plant pathogens from iron nutrition; thereby restricting its growth, and thus, help in biological control of phytopathogens (Shaikh et al. 2014). Besides these, siderophores are also used in pharmaceuticals (Crumbliss and Harrington 2009; Hider and Kong 2010), bioremediation of heavy metal pollutants (Rajkumar et al. 2010), biogeochemical cycling of iron in the ocean (Boyd et al. 2007), biodegradation of petroleum hydrocarbons (Hickford et al. 2004; Gauglitz et al. 2012), and as an optical biosensor (Yoder and Kisaalita 2011; Ahmed and Holmström 2014). Since these molecules have wider range of applications, their production needs to be statistically optimized. Hence, any factor, which influences the production of siderophores in a production medium, needs to be studied.

Non-statistical optimization approach considers only one factor at a time. It is tedious and time-consuming, especially for multi-variable screening, and it does not consider the complex interactions among different variables (Bas and Boyac 2007; Hegde et al. 2013). Statisticalbased approaches offer ideal ways for process-optimization studies in several biochemical and biotechnological processes (Bas and Boyac 2007) such as amylase production 
(Gangadharan et al. 2008; Prajapati et al. 2015), ethanol production (Mei et al. 2009), hydrogen production (Guo et al. 2009), phytase production (Singh and Satyanarayana 2008), avermectin production (Gao et al. 2009), phenazine1-carboxylic acid production ( $\mathrm{Su}$ et al. 2010), cellulose production (Mohite et al. 2012), and cellulase production (Hegde et al. 2013; Thakkar and Saraf 2014). However, there are very few reports on statistical optimization of siderophore production.

Present work focuses on statistical-based optimization approaches, i.e., Plackett-Burman (PB) design and response surface methodology (RSM) by central composite design (CCD), for enhanced production of siderophore by using succinate medium. Scale-up of optimized shake flask protocol to laboratory-scale bioreactor was also studied.

\section{Materials and methods}

\section{Source of culture}

The siderophore-producing bacterial isolate used in this experiment was isolated and identified as Pseudomonas aeruginosa on the basis of biochemical characteristics, 16s rRNA sequencing, Biolog and GC-FAME analysis (Data not shown). The culture was submitted to the gene bank as $P$. aeruginosa RZS9 under National Center for Biotechnology information (NCBI) accession number KP866815.

\section{Production, detection and quantification of siderophore}

Production of siderophore was carried out in erlenmeyer flask containing $100 \mathrm{ml}$ succinate medium (Meyer and Abdallah 1978). For this purpose, P. aeruginosa RZS9 $\left(6 \times 10^{6}\right.$ cells $\mathrm{ml}^{-1}$ corresponding to $0.20 \mathrm{OD}$ units $)$ was grown in succinate medium at $28 \pm 2{ }^{\circ} \mathrm{C}$ at $120 \mathrm{rpm}$ for $24 \mathrm{~h}$, followed by measuring cell density at $620 \mathrm{~nm}$ by using double-beam UV-visible spectrophotometer (1240, Shimadzu, Japan). The detection and estimation of siderophore was performed after centrifugation (15 min at $5000 \mathrm{~g} \times \mathrm{cm}$ at $4{ }^{\circ} \mathrm{C}$ ), and the cell-free supernatant was tested for the presence of siderophore by using CAS test (Schwyn and Neilands 1987). CAS shuttle assay was used for quantitative estimation of siderophore (Payne 1994); in this, $1 \mathrm{ml}$ of the culture supernatant was mixed with $1 \mathrm{ml}$ of CAS reagent. Absorbance was measured at $630 \mathrm{~nm}$ against a reference consisting of $1 \mathrm{ml}$ of uninoculated broth and $1 \mathrm{ml}$ of CAS reagent. Siderophore content in the aliquot was calculated by using the following formula and expressed as percent siderophore unit (SU), which is defined as the percent $(\mathrm{v} / \mathrm{v})$ of siderophore present in the given sample:
$\% \mathrm{SU}=\frac{\mathrm{Ar}-\mathrm{As}}{\mathrm{Ar}} \times 100$

where $\mathrm{Ar}=$ Absorbance of the reference at $630 \mathrm{~nm}$ (CAS reagent), As $=$ Absorbance of the sample at $630 \mathrm{~nm}$.

\section{Designs of experiment}

In the first phase, PB design was used to find the significant variable(s) or factor(s) to optimize the siderophore production. In the next phase, RSM through CCD was used to find the optimum concentration of the selected variable. The effect of selected variables on the responses was analyzed to maximize the siderophore production (Murugappan et al. 2007).

\section{Plackett-Burman design}

In the first phase of the optimization, 11 variable PB experimental design was used to find the significant ingredients of the medium for the maximum production of siderophore (Plackett and Burman 1946). This experimental design was two-factorial design, and was used to identify the critical parameters required for optimum siderophore production by screening $n$ variables in $n+1$ experiment (Plackett and Burman 1946). The components of succinic acid medium chosen for the present study were $\mathrm{K}_{2} \mathrm{HPO}_{4}, \mathrm{KH}_{2} \mathrm{PO}_{4},\left(\mathrm{NH}_{4}\right) \mathrm{SO}_{4}, \mathrm{MgSO}_{4} \cdot 7 \mathrm{H}_{2} \mathrm{O}$ and succinic acid. Physical parameters such as $\mathrm{pH}$ and temperature also influence the siderophore production. These variables were coded as A, B, C, D, E, F and G respectively, while H, I, J, and $\mathrm{K}$ were considered as dummy variables. All the independent variables with their $\mathrm{H}$ and $\mathrm{L}$ value are described in Table 1.

The experimental design for the screening of these variables is presented in Table 2. Experiments of PB design were done in triplicates, and the average mean of SU was considered as the final response. The quantification of siderophore production was done by CAS shuttle assay (Payne 1994). Each of these variables was represented at two different levels-high concentration $(\mathrm{H})$ and low

Table 1 Medium components and their variables used in PlacketBurman design for siderophore production

\begin{tabular}{llll}
\hline Variable code & Variable & High value $(+1)$ & Low value $(-1)$ \\
\hline$A$ & $\mathrm{~K}_{2} \mathrm{HPO}_{4}$ & 0.78 & 0.42 \\
$B$ & $\mathrm{KH}_{2} \mathrm{PO}_{4}$ & 0.39 & 0.21 \\
$C$ & $\left(\mathrm{NH}_{4}\right) \mathrm{SO}_{4}$ & 0.13 & 0.07 \\
$D$ & $\mathrm{MgSO}_{4} \cdot 7 \mathrm{H}_{2} \mathrm{O}$ & 0.026 & 0.014 \\
$E$ & Succinic acid & 0.52 & 0.28 \\
$F$ & $\mathrm{pH}$ & 6 & 8 \\
$G$ & Temperature & 22 & 34 \\
\hline
\end{tabular}


Table 211 variable Plackett-Burman experimental design

\begin{tabular}{|c|c|c|c|c|c|c|c|c|c|c|c|c|}
\hline Run & $A$ & $B$ & $C$ & $D$ & $E$ & $F$ & $G$ & $H$ & $I$ & $J$ & $K$ & $\begin{array}{l}\text { Yield } \\
\% \text { SU }\end{array}$ \\
\hline 1 & $\mathrm{H}$ & $\mathrm{H}$ & $\mathrm{H}$ & $\mathrm{H}$ & $\mathrm{H}$ & $\mathrm{H}$ & $\mathrm{H}$ & $\mathrm{H}$ & $\mathrm{H}$ & $\mathrm{H}$ & $\mathrm{H}$ & 50.94 \\
\hline 2 & $\mathrm{~L}$ & $\mathrm{H}$ & $\mathrm{L}$ & $\mathrm{H}$ & $\mathrm{H}$ & $\mathrm{H}$ & $\mathrm{L}$ & $\mathrm{L}$ & $\mathrm{L}$ & $\mathrm{H}$ & $\mathrm{L}$ & 52.31 \\
\hline 3 & $\mathrm{~L}$ & $\mathrm{~L}$ & $\mathrm{H}$ & $\mathrm{L}$ & $\mathrm{H}$ & $\mathrm{H}$ & $\mathrm{H}$ & $\mathrm{L}$ & $\mathrm{L}$ & $\mathrm{L}$ & $\mathrm{H}$ & 50.14 \\
\hline 4 & $\mathrm{H}$ & $\mathrm{L}$ & $\mathrm{L}$ & $\mathrm{H}$ & $\mathrm{L}$ & $\mathrm{H}$ & $\mathrm{H}$ & $\mathrm{H}$ & $\mathrm{L}$ & $\mathrm{L}$ & $\mathrm{L}$ & 45.84 \\
\hline 5 & $\mathrm{~L}$ & $\mathrm{H}$ & $\mathrm{L}$ & $\mathrm{L}$ & $\mathrm{H}$ & $\mathrm{L}$ & $\mathrm{H}$ & $\mathrm{H}$ & $\mathrm{H}$ & $\mathrm{L}$ & $\mathrm{L}$ & 45.35 \\
\hline 6 & $\mathrm{~L}$ & $\mathrm{~L}$ & $\mathrm{H}$ & $\mathrm{L}$ & $\mathrm{L}$ & $\mathrm{H}$ & $\mathrm{L}$ & $\mathrm{H}$ & $\mathrm{H}$ & $\mathrm{H}$ & $\mathrm{L}$ & 48.36 \\
\hline 7 & $\mathrm{~L}$ & $\mathrm{~L}$ & $\mathrm{~L}$ & $\mathrm{H}$ & $\mathrm{L}$ & $\mathrm{L}$ & $\mathrm{H}$ & $\mathrm{L}$ & $\mathrm{H}$ & $\mathrm{H}$ & $\mathrm{H}$ & 40.65 \\
\hline 8 & $\mathrm{H}$ & $\mathrm{L}$ & $\mathrm{L}$ & $\mathrm{L}$ & $\mathrm{H}$ & $\mathrm{L}$ & $\mathrm{L}$ & $\mathrm{H}$ & $\mathrm{L}$ & $\mathrm{H}$ & $\mathrm{H}$ & 49.35 \\
\hline 9 & $\mathrm{H}$ & $\mathrm{H}$ & $\mathrm{L}$ & $\mathrm{L}$ & $\mathrm{L}$ & $\mathrm{H}$ & $\mathrm{L}$ & $\mathrm{L}$ & $\mathrm{H}$ & $\mathrm{L}$ & $\mathrm{H}$ & 48.01 \\
\hline 10 & $\mathrm{H}$ & $\mathrm{H}$ & $\mathrm{H}$ & $\mathrm{L}$ & $\mathrm{L}$ & $\mathrm{L}$ & $\mathrm{H}$ & $\mathrm{L}$ & $\mathrm{L}$ & $\mathrm{H}$ & $\mathrm{L}$ & 40.86 \\
\hline 11 & $\mathrm{~L}$ & $\mathrm{H}$ & $\mathrm{H}$ & $\mathrm{H}$ & $\mathrm{L}$ & $\mathrm{L}$ & $\mathrm{L}$ & $\mathrm{H}$ & $\mathrm{L}$ & $\mathrm{L}$ & $\mathrm{H}$ & 44.75 \\
\hline 12 & $\mathrm{H}$ & $\mathrm{L}$ & $\mathrm{H}$ & $\mathrm{H}$ & $\mathrm{H}$ & $\mathrm{L}$ & $\mathrm{L}$ & $\mathrm{L}$ & $\mathrm{H}$ & $\mathrm{L}$ & $\mathrm{L}$ & 50.32 \\
\hline
\end{tabular}

concentration (L). The effect of individual variable was determined by calculating the difference between the average of measure at the $\mathrm{H}$ value and the $\mathrm{L}$ value. The full experimental design consisting of 11 variables with four dummy variables and 12 trials is depicted in Table 2 . The effect of each variable on siderophore production in the form of SU was calculated, and the highest confidence level and $f$ test was used to determine the significant component (Stanbury et al. 2003).

\section{Response surface methodology (RSM)}

The second phase in optimization of the medium-component was to find the optimum concentration of the significant components by RSM through CCD. It involved steps such as procedures to find the optimum region, the responses in the optimum region of variables, estimation of the optimal conditions and verification of the data (Tanyildizi et al. 2005). The variables obtained from PB design to enhance the siderophore production were selected for CCD to study the interaction between the various medium constituents, which influence the siderophore production. The CCD was used to study the interaction between the significant components and also to determine their optimum levels. In the present work, experiments were planned to obtain a quadratic model. Hence, the concentrations of the three factors i.e., succinic acid, $\mathrm{pH}$ and temperature, identified by PB design, were optimized, keeping other variables constant at zero (0) level. Each factor was studied at five different levels $(-\alpha,-1,0,+1,+\alpha)$ (Table 3$)$. The complete experimental plan of CCD with respect to their values in coded and actual form is listed in Table 4. SUs
Table 3 Experimental range and levels of the independent variables components used for response surface central composite design

\begin{tabular}{lllllll}
\hline Variable & Components & $-\alpha$ & -1 & 0 & +1 & $+\alpha$ \\
\hline$A$ & Succinic acid & 0.198185 & 0.28 & 0.4 & 0.52 & 0.601815 \\
$B$ & $\mathrm{pH}$ & 5.31821 & 6 & 7 & 8 & 8.68179 \\
$C$ & Temperature & 17.9092 & 22 & 28 & 34 & 38.0908 \\
\hline
\end{tabular}

were measured in triplicate in 20 trial-experimental runs. Design matrix consists of coded terms with eight factorial points, six axial points and five central points. The data were fitted into the second-order polynomial equation, and the coefficients were calculated and analysed. The general form of the second-degree polynomial equation is:

$Y i=\beta 0+\sum \beta i X i+\sum \beta i i X i^{2}+\sum \beta i j X i X j$

where $Y i$ is the predicted response, $X i X j$ are input variables, which influence the response variable $Y, \beta 0$ is the offset term, $\beta i$ is the $i$ th linear coefficient, $\beta i i$ is the quadratic coefficient, $\beta i j$ is the $i j$ th interaction coefficient.

After the analysis of data, the experimental run with optimum values of variable was done to check the validity of the model.

\section{Scale-up on bioreactor}

The shake flask process was scaled-up to 5L capacity fullyautomated laboratory-scale bioreactor [Murhopye Scientific Co., India, Model LF-5] to check the performance of siderophore producing isolate and to confirm the validity of optimization studies carried out at shake flask level. 
Table 4 Analysis of siderophore yield by Plackett-Burman experimental design

\begin{tabular}{lccccccc}
\hline & Difference & Effect & $\begin{array}{l}\text { Mean } \\
\text { square }\end{array}$ & $t$ value & $P$ value & $\begin{array}{l}F \text { value } \\
\text { level }\end{array}$ \\
\hline$A$ & 3.76 & 0.94 & 1.7672 & 4.88819553 & 0.00811258 & 5.7941 & 99.18 \\
$B$ & -2.44 & -0.61 & 0.7442 & -3.17212689 & 0.03378888 & 2.44 & 96.62 \\
$C$ & 3.86 & 0.965 & 1.86245 & 5.01820073 & 0.00739474 & 6.10639 \\
$D$ & 2.74 & 0.685 & 0.93845 & 3.56214249 & 0.02354079 & 3.07689 & 97.64 \\
$E$ & 29.94 & 7.485 & 112.05 & 38.9235569 & $2.6025 \mathrm{E}-06$ & 367.379 & 99.99 \\
$F$ & 24.32 & 6.08 & 73.9328 & 31.6172647 & $5.9644 \mathrm{E}-06$ & 242.403 & 99.99 \\
$G$ & -19.32 & -4.83 & 46.6578 & -25.1170047 & $1.4918 \mathrm{E}-05$ & 152.976 & 99.99 \\
$H$ & 2.3 & 0.575 & 0.66125 & 2.9901196 & ND & ND & ND \\
$I$ & 0.38 & 0.095 & 0.01805 & 0.49401976 & ND & ND & ND \\
$J$ & -1.94 & -0.485 & 0.47045 & -2.52210088 & ND & ND & ND \\
$K$ & 0.8 & 0.2 & 0.08 & 1.0400416 & ND \\
\hline
\end{tabular}

Standard error 0.1923 , Mean square for error $0.305, N D$ not determined

\section{Software and data analysis}

Analysis and interpretation of the data was carried out for the RSM experimental design using Design-Expert version 9.0.3.1 (Stat-Ease Inc., Minneapolis, MN, USA) statistical software.

\section{Results and discussion}

\section{Production, detection and quantification of siderophore}

After $24 \mathrm{~h}$ incubation of inoculated succinate medium, change in the colour of the medium from colourless to fluorescent-green indicated siderophore-producing ability of $P$. aeruginosa RZS9. Positive CAS test, i.e., change in the colour of CAS from blue to orange-yellow confirmed the siderophore production. $P$. aeruginosa RZS9 produced $63.38 \%$ SU. Similar results have been reported by Milagres et al. (1999), Sayyed and Patel (2011), and Shaikh et al. (2014).

\section{Plackett-Burman design}

The medium components are known to have varying effect on the siderophore production. PB design was used to screen seven different medium-components in 12 trial-experimental runs with two levels, high $(\mathrm{H})$ and low $(\mathrm{L})$ of each variable. The independent variables and their respective $\mathrm{H}$ and $\mathrm{L}$ value used in the optimization study, and the response in the form of SU are represented in Table 3, whereas the analysis of the yield by PB experimental design are represented in Table 4, in which the variables showing higher $F$ value are considered as significant and those showing $F$ value near zero (0) are considered as insignificant (Stanbury et al. 2003). Level of significance was also determined by highest confidence level. Hence, succinic acid, $\mathrm{pH}$ and temperature were considered as significant components in siderophore production.

\section{Response surface methodology (RSM)}

To study the combined effect of these three variables, Trials were performed at different combinations of each variable to study the combined effect of these three variables. The CCD experimental plan along with experimental response and the predicted response for each individual experiment is scrutinized in Table 5. It shows the production of siderophore corresponding to the combined effect of all three components in the specific range. The production of siderophore may be predicted by the equation derived by Design-Expert software. This final equation, in terms of Coded Factors, can be used to make predictions about the response for given levels of each factor. Here, the levels should be specified in the original units for each factor.

$$
\begin{aligned}
Y= & +63.94+10.99(A)+3.14(B)-0.34(C) \\
& -1.37(A B)-0.19(A C)+1.12(B C) \\
& -6.76(A)^{2}-11.84(B)^{2}-5.75(C)^{2}
\end{aligned}
$$

where, $Y=\mathrm{SU}$ in $\%, A=$ succinic acid, $B=\mathrm{pH}$, $C=$ temperature.

The statistical significance of the second-order quadratic model was evaluated by $F$ test ANOVA, which revealed that this regression model is at a statistically-higher 
Table 5 Full experimental central composite design with coded and actual level of variables and the response function

\begin{tabular}{|c|c|c|c|c|c|c|c|c|c|}
\hline \multirow[t]{2}{*}{ Run } & \multirow[t]{2}{*}{ Type } & \multicolumn{2}{|c|}{ A:Succinic acid $(\mathrm{g} / 100 \mathrm{ml})$} & \multicolumn{2}{|l|}{$\mathrm{B}: \mathrm{pH}$} & \multicolumn{2}{|c|}{$\mathrm{C}:$ Temperature $\left({ }^{\circ} \mathrm{C}\right)$} & \multicolumn{2}{|c|}{ Siderophore unit $\%$} \\
\hline & & Coded & Actual & Coded & Actual & Coded & Actual & Experimental & Predicted \\
\hline 1 & Factorial & +1 & 0.52 & -1 & 6 & -1 & 22 & 44.67 & 50.02 \\
\hline 2 & Factorial & +1 & 0.52 & +1 & 8 & +1 & 34 & 48.87 & 52.49 \\
\hline 3 & Factorial & -1 & 0.28 & +1 & 8 & -1 & 22 & 29.58 & 32.26 \\
\hline 4 & Axial & $+\alpha$ & 0.601815 & 0 & 7 & 0 & 28 & 70.97 & 61.89 \\
\hline 5 & Axial & 0 & 0.4 & $-\alpha$ & 5.31821 & 0 & 28 & 26.46 & 25.42 \\
\hline 6 & Center & 0 & 0.4 & 0 & 7 & 0 & 28 & 63.97 & 63.93 \\
\hline 7 & Factorial & 0 & 0.52 & +1 & 8 & -1 & 22 & 46.86 & 51.32 \\
\hline 8 & Axial & $-\alpha$ & 0.198185 & 0 & 7 & 0 & 28 & 23.76 & 25.89 \\
\hline 9 & Factorial & -1 & 0.28 & -1 & 6 & -1 & 22 & 25.84 & 25.49 \\
\hline 10 & Factorial & -1 & 0.28 & +1 & 8 & +1 & 34 & 36.28 & 34.21 \\
\hline 11 & Center & 0 & 0.4 & 0 & 7 & 0 & 28 & 63.73 & 63.93 \\
\hline 12 & Axial & 0 & 0.4 & 0 & 7 & $+\alpha$ & 38.0908 & 46.34 & 47.35 \\
\hline 13 & Factorial & -1 & 0.28 & -1 & 6 & +1 & 34 & 24.15 & 22.96 \\
\hline 14 & Axial & 0 & 0.4 & $+\alpha$ & 8.68179 & 0 & 28 & 39.56 & 35.97 \\
\hline 15 & Center & 0 & 0.4 & 0 & 7 & 0 & 28 & 63.27 & 63.93 \\
\hline 16 & Factorial & +1 & 0.52 & -1 & 6 & +1 & 34 & 46.13 & 46.72 \\
\hline 17 & Center & 0 & 0.4 & 0 & 7 & 0 & 28 & 63.42 & 63.93 \\
\hline 18 & Center & 0 & 0.4 & 0 & 7 & 0 & 28 & 64.32 & 63.93 \\
\hline 19 & Axial & 0 & 0.4 & 0 & 7 & $-\alpha$ & 17.9092 & 54.13 & 48.49 \\
\hline 20 & Center & 0 & 0.4 & 0 & 7 & 0 & 28 & 64.08 & 63.93 \\
\hline
\end{tabular}

significance level for siderophore production. The $F$ value of the model was 28.63 , which implies that the model is statistically significant. There is only $0.01 \%$ chance that an $F$ value of this large could occur due to noise. Values of 'Prob $>F$ ' less than 0.0500 indicated that the model is significant (Table 6). The large 'Lack of Fit $F$ value' also indicated that the Lack of Fit is significant. Multiple correlation coefficient $\left(R^{2}\right)$ reflected the adequacy of this model. The $R^{2}$ value of 0.9626 closer to 1 denoted better correlation between predicted and observed values (Gao et al. 2009; Mohite et al. 2012; Thakkar and Saraf 2014). It indicated that the model could explain $96 \%$ of the variability. The coefficient of variation $(\mathrm{CV})$ indicates the degree of precision in which the experiments were compared. The low reliability of the model-experiments was indicated by the high value of CV. In the present case, a low CV (8.81) denoted that the experiments performed are reliable (Gangadharan et al. 2008; Prajapati et al. 2015). 'Adeq Precision' measures the signal to noise ratio. A ratio $>4$ is desirable. Here, the value of 13.932 indicates an adequate signal. Thus, this model can be used to navigate the design space, and the model is best fitted for the optimization studies (Prajapati et al. 2015).
Table 6 Analysis of variance of quadratic model for siderophore production

\begin{tabular}{lrrrrc}
\hline Source & Squares & $d f$ & Square & Value & Prob $>F$ \\
\hline Model & 4455.44 & 9 & 495.05 & 28.63 & $<0.0001$ \\
& & & & & significant \\
$A$-succinic acid & 1564.59 & 1 & 1564.59 & 90.48 & $<0.0001$ \\
$B$-pH & 134.33 & 1 & 134.33 & 7.77 & 0.0192 \\
$C$-temp & 1.56 & 1 & 1.56 & 0.090 & 0.7698 \\
$A B$ & 14.96 & 1 & 14.96 & 0.87 & 0.3742 \\
$A C$ & 0.30 & 1 & 0.30 & 0.017 & 0.8984 \\
$B C$ & 9.99 & 1 & 9.99 & 0.58 & 0.4647 \\
$A^{2}$ & 723.48 & 1 & 723.48 & 41.84 & $<0.0001$ \\
$B^{2}$ & 1989.83 & 1 & 1989.83 & 115.07 & $<0.0001$ \\
$C^{2}$ & 461.76 & 1 & 461.76 & 26.70 & 0.0004 \\
Residual & 172.93 & 10 & 17.29 & & \\
Lack of fit & 172.12 & 5 & 34.42 & 213.05 & $<0.0001$ \\
& & & & & significant \\
Pure error & 0.81 & 5 & 0.16 & & \\
Cor total & 4628.37 & 19 & & & \\
\hline
\end{tabular}

$R^{2}=0.9626, \quad$ Standerd deviation $=4.16, \quad$ CV $\%=8.81, \quad$ Adeq precision $=13.932$

Pred $R^{2}=0.7152$, Adj $R^{2}=0.9290$ 
(a)

Design-Expert@ Software Factor Coding: Actua 68.65

23.76

$\mathrm{X} 1=\mathrm{A}:$ Succinic acid $\mathrm{X} 2=\mathrm{B}: \mathrm{pH}$

Actual Factor

C: Temp $=27.027$

(b)

Design-Expert@ Software Factor Coding: Actual Siderophore unit $(\%)$ - Design Point

X1 = A: Succinic acid

$X_{2}=$ C: Temp

Actual Factor

B: $\mathrm{pH}=7$

Siderophore unit (\%)

- Design Po

23.76

$\mathrm{X} 1=\mathrm{B}: \mathrm{pH}$
$\mathrm{X} 2=\mathrm{C}:$ Temp

Actual Factor

A: Succinic acid $=0.4$ (c) Design-Expert® Software
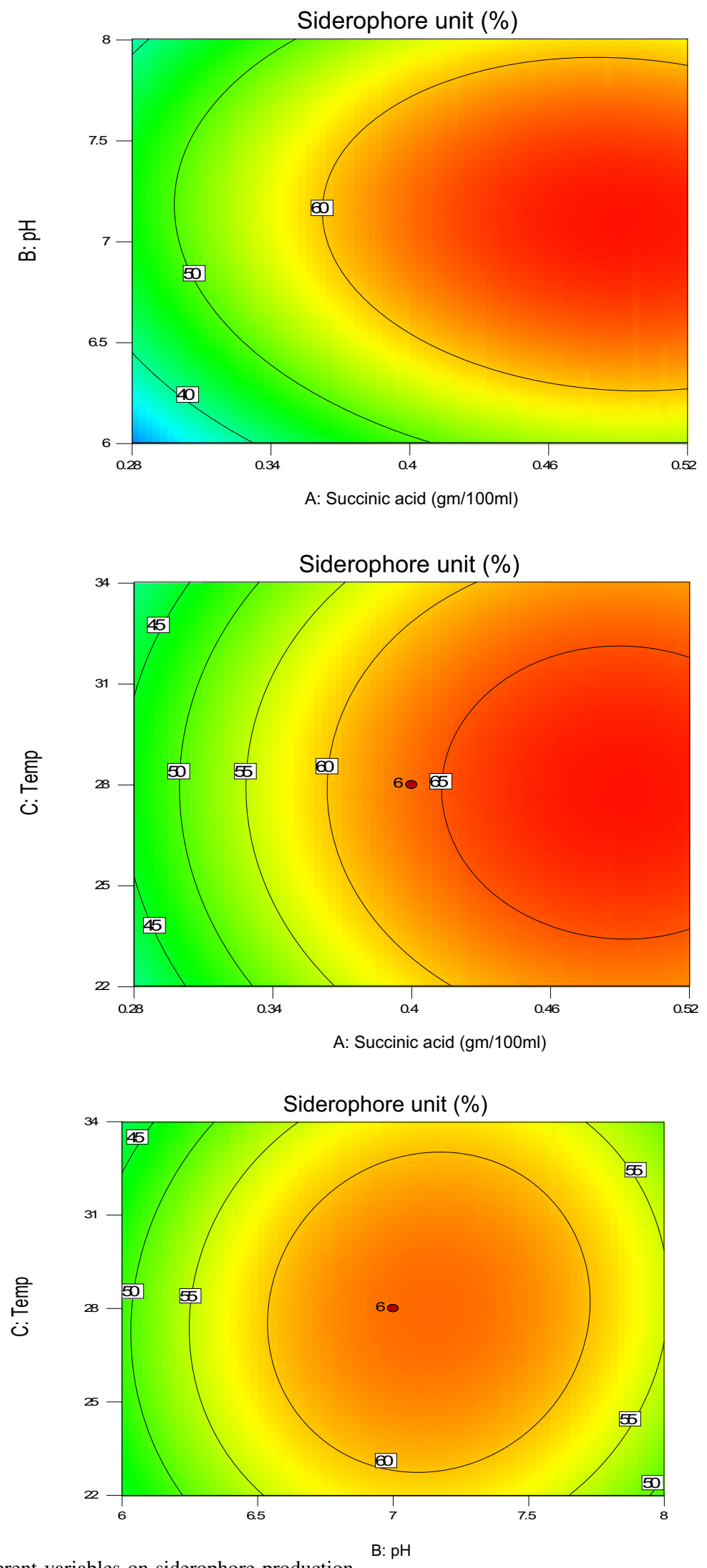

Fig. 1 Counter plots showing interaction of different variables on siderophore production 
(a)

Design-Expert@ Software Factor Coding: Actual

68.65

23.76

$\mathrm{X} 1=\mathrm{A}:$ Succinic acid

$X_{2}=\mathrm{B}: \mathrm{pH}$

Actual Factor

C. Temp $=27.027$

(b)

Design-Expert( 8 Software

Siderophore unit (\%)

- Design points above predicted value

68.65

$\mathrm{X}_{1}=\mathrm{A}$ : Succinic acid

X1 $=$ A: Succinic
X2 $=$ C: Temp

Actual Factor
B: $\mathrm{pH}=7$

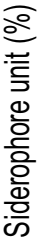

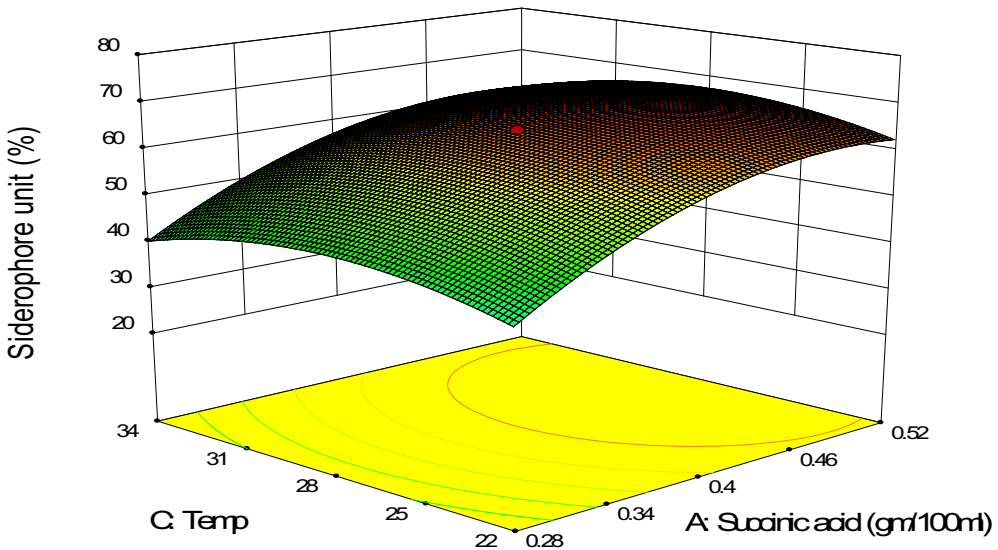

(c)

Design-Expert@ Software

erophore unit (\%)

- Design points above predicted value

68.65
23.76

$\mathrm{X} 1=\mathrm{B}: \mathrm{pH}$
$\mathrm{X} 2=\mathrm{C}:$ Temp

Actual Factor

A: Succinic acid $=0.4$

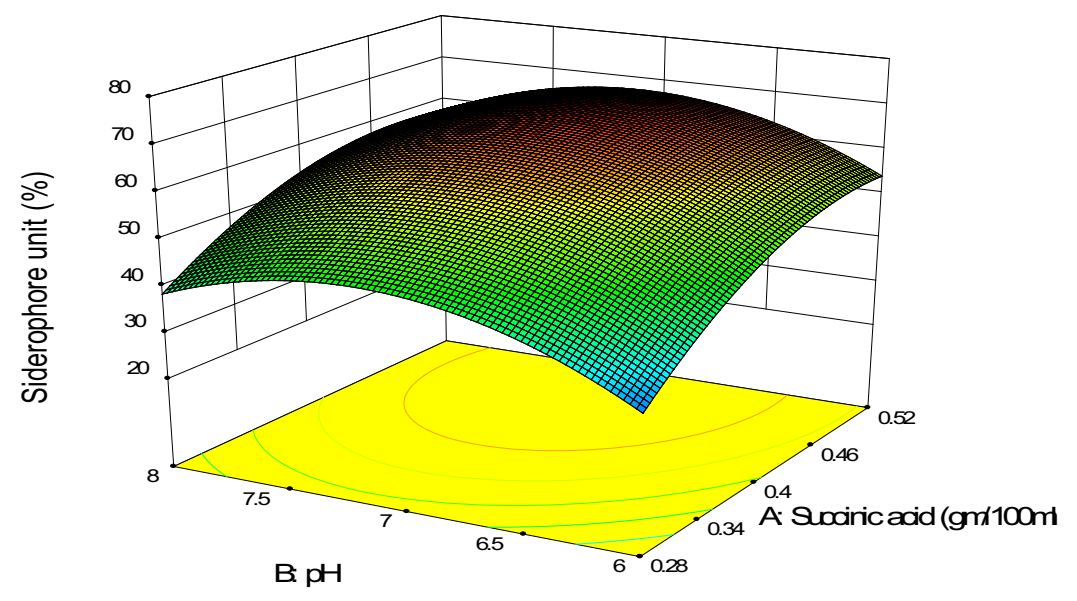


Fig. 3 Pertubation plot for siderophore production as function of ammonium sulphate and succinic acid
Design-Expert $₫$ Software Factor Coding: Actual Siderophore unit (\%)

Actual Factors B: $\mathrm{pH}=7$ A: Succinic acid $=0.4$

C: Temp $=27.027$

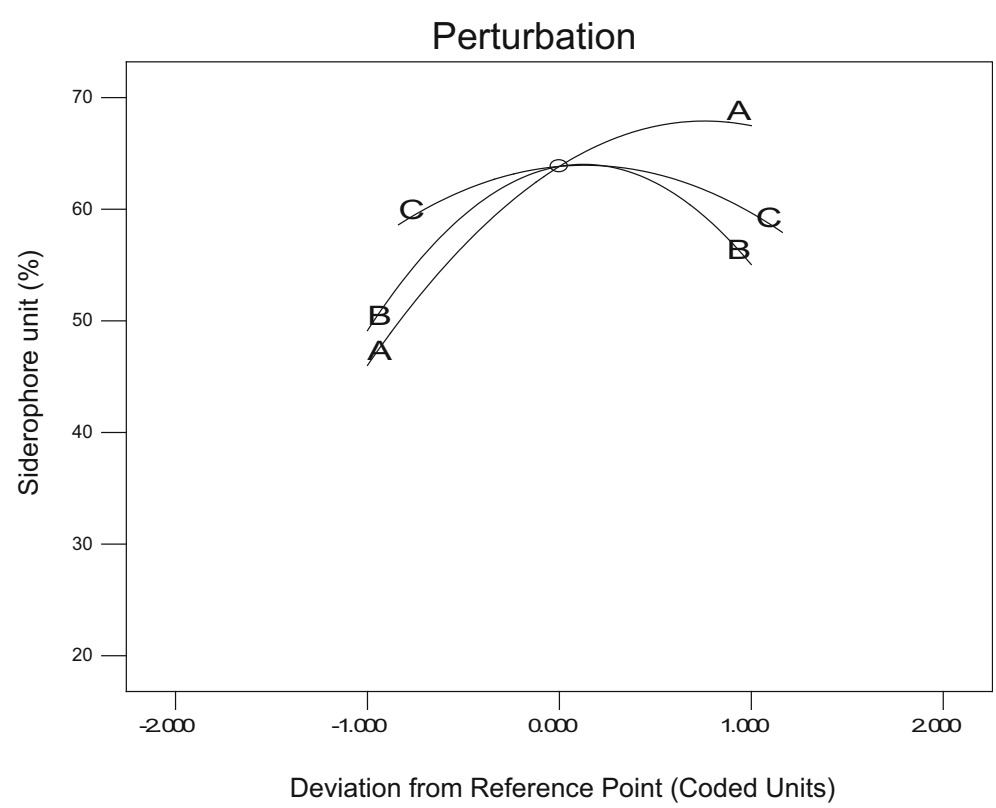

Design-Expert $\circledast$ Software Factor Coding: Actual Overlay Plot

Siderophore unit CI Low

$x_{1}=A$ : Succinic acid $\mathrm{X} 2=\mathrm{B}: \mathrm{pH}$

Actual Factor C: Temp $=27.8061$

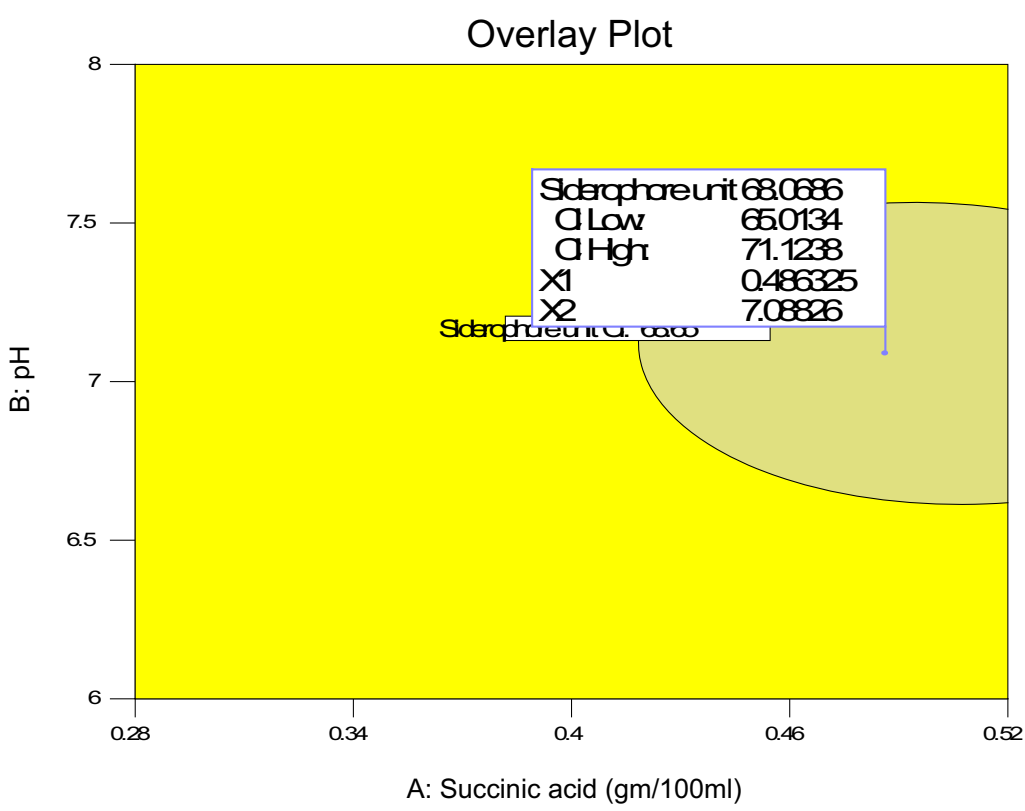

The effect of variables on siderophore production was studied against three independent variables while maintaining the other independent variables at their zero (0) level. The three dimensional (3D) response surface plots were drawn to understand the interaction between medium components, and the optimum concentration of each variable required for maximum siderophore production. These contour plots (Fig. 1a-c) or 3D response surface plots (Fig. 2ac) can be used to predict the optimal values for various test variables. Contour plots indicate the area of operability within the experimental region and helps to characterize the responses. These plots were obtained by considering all the possible combinations of all the variables under test. As observed in the 3D response surface plots, the shape of the curve shows a moderate interaction between any two variables when the third variable is constant.

The effect of all the three factors on siderophore production as studied by perturbation plot in which comparison of the effect of all the factors at the zero (0) values (midpoint) in the design space was carried out, yielded a steep curvature or slope indicating the sensitivity of response to these factors (Fig. 3). As shown in Fig. 4, the concentration of succinic acid (X1) $0.49 \mathrm{~g} / 100 \mathrm{ml}$ at $\mathrm{pH}$ (X2) 7.08 and temperature of $27.80{ }^{\circ} \mathrm{C}$ yielded maximum (68.41\%) SU.

Validation of the experiment was carried out under the conditions predicted by the statistical model. The optimum 
concentrations estimated for the concentration of succinic acid (X1) $0.49 \mathrm{~g} / 100 \mathrm{ml}$ at $\mathrm{pH}(\mathrm{X} 2) 7.08$ at a constant value of temperature $27.80{ }^{\circ} \mathrm{C}$, yielded the maximum siderophore production of $68.41 \%$. Additional experiments in triplicate were carried out with the above-mentioned optimized medium to validate the predictions of the model. These experiments yielded the maximum siderophore production of $69.03 \%$. Hence, it is proved that the experimental results verified the validity predicted by the Design-Expert and the experimental results also confirm the optimal points.

\section{Scale-up on bioreactor}

Scale-up of the shake flask optimized protocol to $5 \mathrm{~L}$ capacity reactor resulted in further increase in siderophore yield by $1 \% .69 .48 \%$ siderophore yield was obtained after $24 \mathrm{~h}$ incubation in bioreactor. This confirmed the validity of optimization studies carried out at shake flask level.

\section{Conclusion}

The statistical-based optimization offered an efficient and feasible approach. A $6.10 \%$ increase in siderophore production was achieved with the optimized factors-concentration of succinic acid (X1) $0.49 \mathrm{~g} / 100 \mathrm{ml}$ at $\mathrm{pH}$ (X2) 7.08 at constant value of temperature $27.80{ }^{\circ} \mathrm{C}$. This set up yielded the maximum siderophore production of $68.41 \%$ vis-à-vis $63.58 \%$ SU obtained in unoptimized protocol. Further increase in siderophore yield by $1 \%$, validated the success of scale-up studies to laboratory-scale bioreactor. The experimental values agreed with the predicted values generated by Design-Expert software.

Acknowledgments The authors are thankful to Prof. K. C. Patel, BRD School of Biosciences, Sardar Patel University, Vallabh Vidyanagar, Gujarat, India for his valuable help in calculating $P$ value and confidence level.

\section{Compliance with ethical standards}

Conflict of interest All authors declare no conflict of interest.

Open Access This article is distributed under the terms of the Creative Commons Attribution 4.0 International License (http://creativecommons. org/licenses/by/4.0/), which permits unrestricted use, distribution, and reproduction in any medium, provided you give appropriate credit to the original author(s) and the source, provide a link to the Creative Commons license, and indicate if changes were made.

\section{References}

Ahmed E, Holmström SJM (2014) Siderophores in environmental research: roles and applications. Microbial Biotechnol 7(3):196-208
Bas D, Boyac IH (2007) Modeling and optimization I: usability of response surface methodology. J Food Eng 78:836-845

Boyd PW, Jickells T, Law CS, Blain S, Boyle EA, Buesseler KO et al (2007) Mesoscale iron enrichment experiments 1993-2005: synthesis and future directions. Science 315:612-617

Crumbliss AL, Harrington JM (2009) Iron sequestration by small molecules: thermodynamic and kinetic studies of natural siderophores and synthetic model compounds. Adv Inorg Chem 61:179-250

Gangadharan D, Sivaramakrishnan S, Nampoothiri KM, Sukumaran RK, Pandey A (2008) Response surface methodology for the optimization of alpha amylase production by Bacillus amyloliquefaciens. Bioresour Technol 99:4597-4602

Gao H, Liu M, Liu J, Dai H, Zhou X, Liu X, Zhuo Y, Zhang L (2009) Medium optimization for the production of avermectin B1a by Streptomyces avermitilis $14-12 \mathrm{~A}$ using response surface methodology. Bioresour Technol 100:4012-4016

Gauglitz JM, Zhou H, Butler A (2012) A suite of citrate-derived siderophores from a marine Vibrio species isolated following the Deepwater Horizon oil spill. J Inorg Biochem 107:90-95

Guo WQ, Ren NQ, Wang XJ, Xiang WS, Ding J, You Y, Liu BF (2009) Optimization of culture conditions for hydrogen production by Ethanoligenens harbinense B49 using response surface methodology. Bioresour Technol 100:1192-1196

Hegde S, Bhadri G, Narsapur K, Koppal S, Oswal P et al (2013) Statistical optimization of medium components by response surface methodology for enhanced production of bacterial cellulose by Gluconacetobacter persimmonis. J Bioprocess Biotech 4:142

Hickford SJH, Küpper FC, Zhang G, Carrano CJ, Blunt JW, Butler A (2004) Petrobactin sulfonate, a new siderophore produced by the marine bacterium Marinobacter hydrocarbonoclasticus. J Nat Prod 67:1897-1899

Hider RC, Kong X (2010) Chemistry and biology of siderophores. Nat Prod Rep 27:637-657

Mei XR, Shen Liu F, Wu H (2009) Optimization of fermentation conditions for the production of ethanol from stalk juice of sweet sorghum by immobilized yeast using response surface methodology. Energy Fuels 23:487-491

Meyer JM, Abdallah MA (1978) The Fluorescent pigments of Fluorescent Pseudomonas: biosynthesis, purification and physicochemical properties. J Gen Microbiol 107:319-328

Milagres AMF, Machuca A, Napoleao D (1999) Detection of siderophore production from several fungi and bacteria by a modification of chrome Azurol S (CAS) agar plate assay. J Microbiol Methods 37:1-6

Mohite BV, Kamalja KK, Patil SV (2012) Statistical optimization of culture conditions for enhanced bacterial cellulose production by Gluconoacetobacter hansenii NCIM 2529. Cellulose 19:1655-1666

Murugappan RM, Aravinth A, Rajaroobia R, Karthikeyan M, Alamelu MR (2007) Optimization of MM9 medium constituents for enhancement of siderophoregenesis in marine Pseudomonas putida using response surface methodology. Indian J Microbiol 52(3):433-441

Payne SM (1994) Detection, isolation and characterization of Siderophores. In: Clark VL, Bovil PM (eds) Methods enzymol. Academic press, New York, pp 329-344

Plackett RL, Burman JP (1946) The design of optimum multifactorial experiments. Biometrika 33:305-325

Prajapati VS, Trivedi UB, Patel KC (2015) A statistical approach for the production of thermostable and alklophilic alpha-amylase from Bacillus amyloliquefaciens KCP2 under solid-state fermentation. 3 Biotech 5:211-220 
Rajkumar MAN, Prasad MNV, Freitas H (2010) Potential of siderophore-producing bacteria for improving heavy metal phytoextraction. Trends Biotechnol 28:142-149

Sayyed RZ, Patel RP (2011) Biocontrol potential of siderophore producing heavy metal resistant Alcaligenes sp. and Pseudomonas aeruginosa RZS3 vis-à-vis organophosphorus fungicide Indian. J Microbiol 51(3):266-272

Sayyed RZ, Chincholkar SB, Reddy MS, Gangurde NS, Patel PR (2013). Siderophore Producing PGPR for Crop Nutrition and Phytopathogen Suppression In: Maheshwari DK (ed), Bacteria in Agrobiology: Disease Management, pp. 449-471

Schwyn R, Neilands JB (1987) Universal chemical assay for detection and determination of siderophores. Anal Biochem 160:47-56

Shaikh SS, Patel PR, Patel SS, Nikam SD, Rane TU, Sayyed RZ (2014) Production of biocontrol traits by banana field fluorescent pseudomonads and their comparison with chemical fungicides. Ind J Exp Biol 52(9):917-920

Singh B, Satyanarayana T (2008) Improved phytase production by a thermophilic mould Sporotrichum thermophile in submerged fermentation due to statistical optimization. Bioresour Technol 99:824-830

Stanbury PF, Whitaker A, Hall SJ (2003) Principle of fermentation technology, 2nd edn. Butterworth-Hienemann, Elsevier Science, Burlington, pp 125-128

Su JJ, Zhou Q, Zhang HY, Li YQ, Huang XQ, Xu YQ (2010) Medium optimization for phenazine-1-carboxylic acid production by a gacA qscR double mutant of Pseudomonas sp. M18 using response surface methodology. Biores Technol 101:4089-4095

Tanyildizi MS, Ozer D, Elibol M (2005) Optimization of $\alpha$-amylase production by Bacillus sp. using response surface methodology. Proc Biochem 40:2291-2296

Thakkar A, Saraf M (2014) Application of statistically based experimental designs to optimize cellulase production and identification of gene. Nat Prod Bioprospect 4:341-351

Yoder MF, Kisaalita WS (2011) Iron specificity of a biosensor based on fluorescent pyoverdin immobilized in sol-gel glass. J Biol Eng 5:4-16 